\section{An open innovation approach to co-produce scientific knowledge: an examination of citizen science in the healthcare ecosystem}

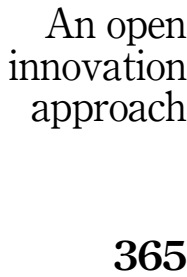

\author{
Maria Vincenza Ciasullo
}

Department of Management and Innovation Systems, University of Salerno, Fisciano, Italy

Mariarosaria Carli

ISMed CNR, Napoli, Italy

Weng Marc Lim

Swinburne University of Technology, Sarawak Campus, Kuching, Malaysia, and

Rocco Palumbo

Management and Law, University of Rome Tor Vergata, Roma, Italy

\begin{abstract}
Purpose - The article applies the citizen science phenomenon - i.e. lay people involvement in research endeavours aimed at pushing forward scientific knowledge - to healthcare. Attention is paid to initiatives intended to tackle the COVID-19 pandemic as an illustrative case to exemplify the contribution of citizen science to system-wide innovation in healthcare.

Design/methodology/approach - A mixed methodology consisting of three sequential steps was developed. Firstly, a realist literature review was carried out to contextualize citizen science to healthcare. Then, an account of successfully completed large-scale, online citizen science projects dealing with healthcare and medicine has been conducted in order to obtain preliminary information about distinguishing features of citizen science in healthcare. Thirdly, a broad search of citizen science initiatives targeted to tackling the COVID-19 pandemic has been performed. A comparative case study approach has been undertaken to examine the attributes of such projects and to unravel their peculiarities.

Findings - Citizen science enacts the development of a lively healthcare ecosystem, which takes its nourishment from the voluntary contribution of lay people. Citizen scientists play different roles in accomplishing citizen science initiatives, ranging from data collectors to data analysts. Alongside enabling big data management, citizen science contributes to lay people's education and empowerment, soliciting their active involvement in service co-production and value co-creation.

Practical implications - Citizen science is still underexplored in healthcare. Even though further evidence is needed to emphasize the value of lay people's involvement in scientific research applied to healthcare, citizen science is expected to revolutionize the way innovation is pursued and achieved in the healthcare ecosystem. Engaging lay people in a co-creating partnership with expert scientist can help us to address unprecedented health-related challenges and to shape the future of healthcare. Tailored health policy and management interventions are required to empower lay people and to stimulate their active engagement in value co-creation.

value co-creation.
\end{abstract}

(C) Maria Vincenza Ciasullo, Mariarosaria Carli, Weng Marc Lim and Rocco Palumbo. Published by Emerald Publishing Limited. This article is published under the Creative Commons Attribution (CC BY 4.0) licence. Anyone may reproduce, distribute, translate and create derivative works of this article (for both commercial and non-commercial purposes), subject to full attribution to the original publication and authors. The full terms of this licence may be seen at http://creativecommons.org/licences/by/4.0/ legalcode
Received 25 February 2021 Revised 15 June 2021 7 August 2021

Accepted 10 August 2021 
EJIM

25,6

Originality/value - Citizen science relies on the wisdom of the crowd to address major issues faced by healthcare organizations. The article comes up with a state of the art investigation of citizen science in healthcare, shedding light on its attributes and envisioning avenues for further development.

Keywords Citizen science, People engagement, Research, Innovation, Co-creation

Paper type Research paper

\section{Introduction}

Healthcare is undergoing a profound process of institutional, technological, and social change (Lega and Palumbo, 2021). Such a transition reframes the innovation processes of healthcare institutions, revising conventional management and organizational practices in light of the opportunities disclosed by digitization (Kraus et al., 2021). Three phenomena are driving the future of innovation in healthcare (Lee and Lim, 2018): the computerization and datification of health services, the transition toward personalized medicine, and the adoption of a peoplecentred approach to drive the functioning of the healthcare system (see, among others: Lim and Ting, 2012; Thakur et al., 2012; Thimbleby, 2013; Lim, 2016; Pianykh et al., 2020). The conjoint action of these three phenomena brings us towards an ecosystem view of healthcare (Lim, 2021; Randhawa et al., 2020). The ecosystem metaphor conceives healthcare as a “... relatively self-contained self-adjusting system of resource integrating actors connected by shared institutional logics and mutual value creation through service exchange" (Akaka and Vargo, 2014, p. 368).

Understanding healthcare as a service ecosystem requires the adoption of an open innovation perspective to envision the future shapes of health services' design and delivery (Barile and Polese, 2010; Ciasullo et al., 2017; Secundo et al., 2019). Indeed, the ecosystem metaphor assumes that the actors who participate in the healthcare service system enter a cocreating partnership (Palumbo et al., 2017), which enables them to share information and resources with the purpose of co-producing innovations intended to advance the quality and the appropriateness of care (Sehgal and Gupta, 2019; Schiavone et al., 2021). Interorganizational relationships represent the most common instruments employed by healthcare institutions to recontextualize their innovation activities according to an open approach (Thune and Gulbrandsen, 2017; Schiavone et al., 2020). Alongside increasing the healthcare institutions' capability of to anticipate evolutions of the task environment, interorganizational relationships enhance the collective effectiveness to address innovation processes and practices in the healthcare ecosystem, exploiting synergies among different institutions (Schiavone and Simoni, 2019).

More recently, increasing attention has been paid to the role of users in driving innovation and in co-creating novel health services' delivery models inspired to a patient-centred perspective (Lundberg et al., 2013; Wass and Vimarlund, 2016; Ciasullo et al., 2020). Literature has articulated heterogeneous frameworks to conceptualize users' engagement in an openinnovation effort aimed at achieving organizational excellence, such as patient-led innovation (McNichol, 2012) and patient involvement in the design of risk prevention and health promotion initiatives (Pushparajah et al., 2015). Lay people engagement enables healthcare institutions to collect timely and rich information about users' preferences and expectations, as well as about their health-related needs, thus adding to the timeliness and effectiveness of innovative approaches intended to improving the functioning of the healthcare ecosystem (Magnusson et al., 2017).

Lay people may play a variety of role in open innovation (Palumbo et al., 2021). Even though patient involvement has been generally targeted to the collection of big data to solicit advancements in scientific research (Beier et al., 2019), users can perform several tasks that are crucial to set the conditions for innovation (Bjørkquist et al., 2015). In particular, patients can be embedded in professional networks, collaborating with professionals to give shapes to 
innovation processes and practices (Pauget and Wald, 2018). Inter alia, citizen science is arising as an open-innovation model that is reconfiguring the way scientific research and innovation activities are accomplished in the healthcare ecosystem (Gristwood, 2019). Citizen science is conceived of as "... the general public engagement in scientific research activities when citizens actively contribute to science either with their intellectual effort or surrounding knowledge or with their tools and resources" (Broeder et al., 2018, p. 506). Citizen scientists participate in collecting, classifying, analyzing, and reporting evidence about scientific issues, providing expert scientists with a support to perform time-expensive activities that are instrumental to knowledge generation and, consequently, to innovation (Wiggins and Wilbanks, 2019).

As previously anticipated, citizen science may be targeted to heterogeneous outcomes, ranging from the collection of large amounts of data to foster the transition towards personalized medicine (Petersen et al.,2020) to lay people's empowerment in order to boost their participation in health services' co-production (Bonney et al., 2016a, b; Palumbo, 2016) and value co-creation (Tran et al., 2019). From this point of view, citizen science can be targeted to achieving different targets, ranging from the implementation of incremental improvements to enhance the appropriateness and the efficiency of healthcare to the development of disruptive solutions to rethink health services' design and delivery (Buyx et al., 2017; Benis et al., 2021). However, management, organizational, and ethical concerns affect the exploitation of citizen science to boost innovation in the healthcare ecosystems (Borda et al., 2019; Petersen et al., 2020). Even though citizen science represents a phenomenon which is modifying the way actors in the healthcare ecosystem collaborate to create innovative solutions aimed at health promotion and risk prevention (Yeung et al., 2020), previous studies have cautioned about the rhetoric of lay people's involvement in healthcare (Woolley et al., 2016).

These considerations call for a more comprehensive understanding of the attributes of citizen science as an open innovation approach. Also, they stress the need for additional research intended to illuminate the challenges that undermine the implementation of citizen science. Among others, three main gaps prevent us from fully acknowledging the contribution of citizen science to healthcare innovation. Firstly, little is known about the distinguishing attributes of citizen science in healthcare: this does not allow us to delineate the models of lay people's involvement in knowledge co-production (Skarlatidou et al., 2019). Secondly, there is limited agreement about the reality of citizen science in the healthcare ecosystem; therefore, it is hard to overcome the rhetoric about lay people's involvement in healthcare-related innovations (Fiske et al., 2019). Thirdly, insights into the citizen science's contribution in enacting an ecosystem response to unprecedented challenges that undermine the sustainability of healthcare organizations are still missing (Ulahannan et al., 2020). These gaps darken the value of open-innovation in healthcare.

The article intends to fill in these voids, contributing to the advancement of what we currently know about the role of citizen science in enacting virtuous innovation dynamics in the healthcare ecosystem. Going more into details, three research questions (RQs) nurtured this study:

$R Q 1$. What are the attributes of citizen science approaches that are implemented to sustain innovation in healthcare?

$R Q 2$. What is the role of lay people in co-producing knowledge and co-creating value in healthcare-related citizen science projects?

$R Q 3$. How does citizen science contribute to addressing unprecedented challenges that put the viability of the healthcare ecosystem under stress?

A mixed research design was arranged to answer these research questions, consisting of a realist literature review combined with a multiple case study. The rest of the article 
EJIM

25,6

\section{8}

progresses as follows. Section 2 describes the methods employed to collect evidence about the characteristics of citizen science in healthcare. It is articulated in three subsections, that provide a detailed account of the study methodology. Section 3 reports the research findings, providing some food for thought to advance what we currently know about citizen science in healthcare. Findings are critically discussed in Section 4, which emphasizes the study's contribution to theory and practice. Section 5 concludes the paper, acknowledging the research limitations and emphasizing its management implications.

\section{Methods}

\subsection{Research strategy}

Figure 1 portrays the mixed methodology which was arranged to answer the three RQs inspiring this article. A similar research design has been used in previous studies focusing on different research topics (Gremyr and Raharjo, 2013; Greenhalgh et al., 2016). It was articulated in three steps, which were reciprocally related and fully consistent with the study aims. A realist literature review was conducted to achieve a comprehensive contextualization of citizen science as an open-innovation model to be applied to the healthcare ecosystem (Step 1). The realist review allowed us to build a theoretical foundation for the two ensuing steps. The decision to undertake a realist review was motivated by the purpose of identifying and explaining the interaction between the context (healthcare ecosystem), the mechanism (citizen science as an open-innovation model) and outcome (the enhancement of risk prevention and health promotion initiatives) investigated in this study (Bergerum et al., 2019). Since we did not intend to systematize what is currently known about citizen science in the healthcare context and we were not interested in articulating an overview of extant publication trends in this research field, neither a systematic literature review nor a bibliometric analysis were contemplated in crafting the study design. Drawing on the insights obtained from the realist review, a comparative case study was conducted on completed healthcare-related citizen science projects to outline the key attributes of lay people's involvement in research and innovation activities implemented by healthcare institutions (Step 2). Lastly, a further

\begin{tabular}{|c|c|c|c|}
\hline & Focus & Purpose & Expected outcome \\
\hline $\begin{array}{l}\text { Step } 1 \\
\begin{array}{c}\text { Realist Literature } \\
\text { Review }\end{array}\end{array}$ & $\begin{array}{l}\text { Analysis of the interplay } \\
\text { between the context } \\
\text { (healthcare), } \\
\text { mechanism (citizen } \\
\text { science) and outcome } \\
\text { (open-innovation) }\end{array}$ & $\begin{array}{l}\text { Collection of } \\
\text { preliminary insights to } \\
\text { address the case study } \\
\text { analysis of CS projects } \\
\text { implemented in the } \\
\text { healthcare domain }\end{array}$ & $\begin{array}{c}\text { Development of a } \\
\text { conceptual background } \\
\text { to contextualize CS to } \\
\text { healthcare }\end{array}$ \\
\hline $\begin{array}{c}\text { Step } 2 \\
\text { Comparative case } \\
\text { study on completed } \\
\text { CS project in the } \\
\text { healthcare field }\end{array}$ & $\begin{array}{l}\text { Investigation of } \\
\text { completed on-line CS } \\
\text { projects focused on } \\
\text { health-related issues } \\
\text { and on medicine- } \\
\text { related topics }\end{array}$ & $\begin{array}{c}\text { Analysis of the } \\
\text { distinguishing attributes of } \\
\text { CS projects implemented in } \\
\text { healthcare and } \\
\text { investigation of lay people's } \\
\text { roles }\end{array}$ & $\begin{array}{c}\text { Arrangement of a } \\
\text { taxonomy to shed light } \\
\text { on lay people's } \\
\text { contribution to value co- } \\
\text { creation }\end{array}$ \\
\hline $\begin{array}{c}\text { Step } 3 \\
\text { Comparative case } \\
\text { study on completed } \\
\text { CS project targeted } \\
\text { to COVID-19 }\end{array}$ & $\begin{array}{l}\text { In-depth examination of } \\
\text { extant CS projects } \\
\text { targeted at involving lay } \\
\text { people to handle the } \\
\text { evolving challenges raised } \\
\text { by COVID-19 }\end{array}$ & $\begin{array}{l}\text { Enhancing our } \\
\text { understanding of lay } \\
\text { people's role in } \\
\text { partnering with expert } \\
\text { scientists to overcome } \\
\text { COVID-19 }\end{array}$ & $\begin{array}{l}\text { Contextualization of CS } \\
\text { to an unprecedented } \\
\text { health challenge to } \\
\text { obtain conceptual and } \\
\text { practical take-aways }\end{array}$ \\
\hline
\end{tabular}

Figure 1.

An overview of the study design 
comparative case-study analysis was run on recently launched citizen science projects intended to tackle the extraordinary challenges brought by the COVID-19 pandemic on the viability of healthcare ecosystems across the world (Step 3). This study design permitted us to contextualize citizen science to healthcare and to shed light into avenues for further developments.

\subsection{The realist literature review}

A realist approach was taken to conduct a literature review about citizen science in healthcare. The realist approach is considered to be especially consistent to investigate complex social phenomena (Pawson et al., 2005) which entail large and system-wide transformations in the healthcare ecosystem (Best et al., 2012). The main aim of a realist review is to obtain insights into the relationships between the context, the mechanisms, and the results of phenomena being examined based on theoretically-grounded assumptions (Bendermacher et al., 2017).

A systematic design was implemented to retrieve scientific contributions to be included in this realist review. Two citation databases were concomitantly queried to collect relevant items. As recommended by literature (Bergman, 2012), both Elsevier's Scopus and Clarivate Analytics' Web of Science (WoS) were interrogated. On the one hand, Scopus records a catalogue consisting of more than 5,000 publishers and accounting from more than 75 million items. On the other hand, WoS is presented as the world's most trusted publisherindependent global citation database, indexing about two billion cited references from over 171 million records. Since these two sources provided us with a comprehensive access to extant scientific literature, other sources, such as Google Scholar and other citation databases, were not queried (Pranckute, 2021).

A standard search string was run in the search engines of the two citation databases. The authors had a meeting to identify a query that was consistent with the study aims and - at the same time - facilitated the elicitation of the largest number of scientific contributions focusing on citizen science in the healthcare context. The search string consisted of a primary and a secondary term. Attention was primarily paid to the "citizen science" concept, which represented the main topic of interest for this study. In order to account for all the potential variations of this construct, the term "citizen sci*" was used as the primary search term, with the asterisk (*) allowing us to contemplate different articulations of this concept. The secondary research term was related to the particular context that was analyzed in this study. In order to contemplate different spelling conventions, both "health care" and "healthcare" were included in the query. The resulting research string was implemented for "article title, abstract and keywords" on Scopus and for "topic" on WoS. The final query was hit on February, 15th 2021 and led to the collection of 112 scientific contributions.

A preliminary screening analysis was conducted to refine the initial dataset. Duplicates and articles not available in English language were retracted. Besides, records that were not accompanied by an abstract were not taken into consideration. Next, an examination of titles, abstracts, and keywords of remaining items was performed. Three exclusion criteria were formulated: (1) the items that did not focus on the contribution of citizen science to research and innovation in the healthcare context were rejected as "off scope"; (2) the items that did not delve into the role of lay people in co-producing knowledge in the healthcare ecosystem were removed as "off topic"; and (3) the items that did not provide adequate evidence into the value of citizen science for innovation purposes were dismissed as "off purpose".

Figure 2 displays a flow diagram that graphically articulates the process of items' screening. The authors independently analyzed the records in light of the exclusion criteria reported above. A meeting was held to discuss consistencies amongst authors' analysis. When inconsistencies were met, a discussion was started to reach a consensus. An agreement 
EJIM
25,6

\section{0}

Figure 2.

Realist literature review flow-chart

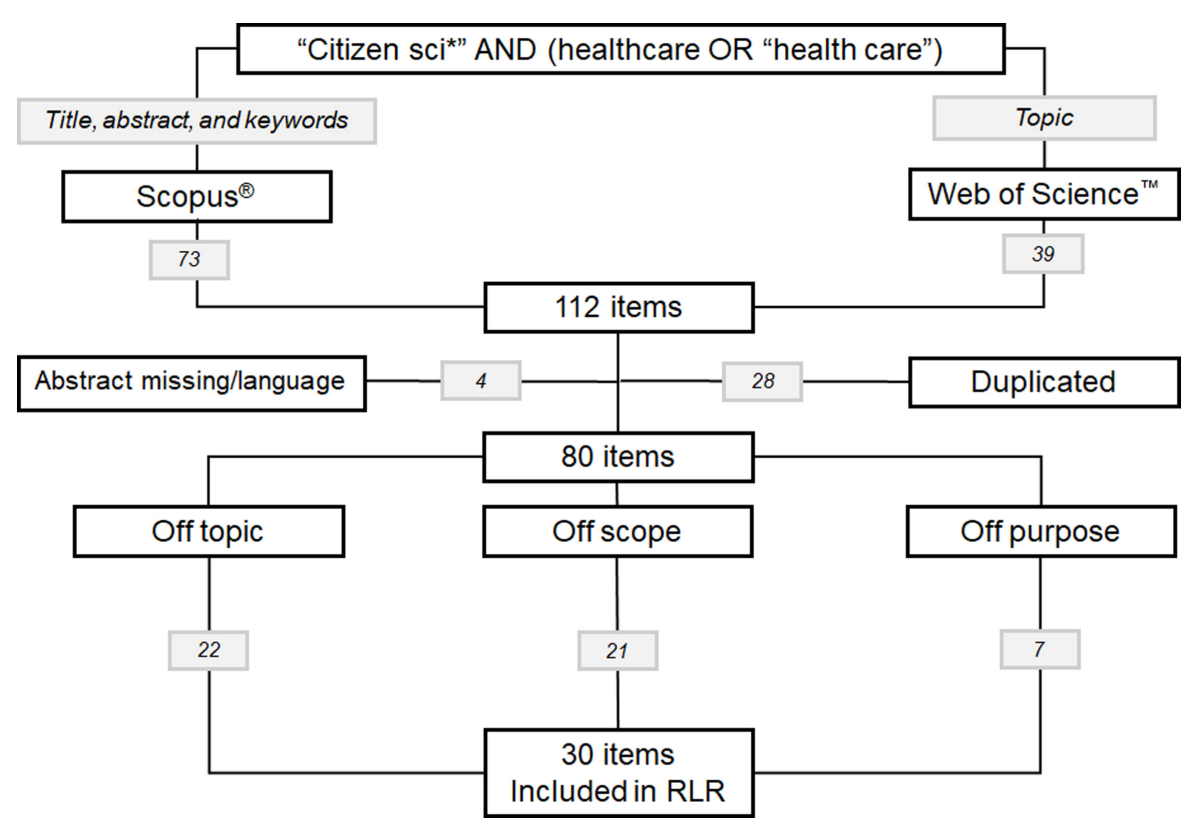

was found when most of the authors (three in four authors) were consistent either in rejecting or in maintaining the disputed items. As a result, 30 items were included in this realist review. A narrative approach was taken to substantiate the report of this literature review.

\subsection{The case analysis on completed citizen science projects}

A comparative case study was accomplished on three finalized citizen science projects hosted by Zooniverse and concerning healthcare-related issues. Zooniverse is one of the most popular web-based platform for citizen science research (Simpson et al., 2014). It is powered by the Citizen Science Alliance, a collaboration of scientists and software developers utilizing people-centred research through internet-based citizen science projects (Masters et al., 2016). To select the citizen science initiatives to be examined in the case analysis, all the projects listed as "finished" as of February 2021 were taken into consideration. Three projects that fell in the medicine/healthcare area were analyzed: "Where are my body organs", "Etch a cell", and "Cell sliders".

Secondary sources were collected to obtain information about these projects and to shed light on lay people's contribution to knowledge co-production. More specifically, three different sources were queried: the Zooniverse platform, the web pages dedicated to the three projects, and additional data retrieved in social media and other web-based sources. Data about these three projects were stored in an electronic worksheet, which was shared amongst the authors. A manual coding approach was used to systematize evidence about these three projects. The coding was intended to elicit information about: (1) the method used to recruit participant, (2) the process of lay people training, and (3) the engagement of lay people in the accomplishment of research activities. The authors independently analyzed collected data and prepared an individual report for each project. A meeting was held to exchange individual perspectives and to achieve a consensus about the distinguishing characteristics of each citizen science project. At the end of the meeting, the authors agreed on a final report, which inspired the articulation of the findings presented below in Section 3. 
The last step of this study consisted of a comparative case-study analysis of current citizen science projects aimed at engaging lay people in tackling the unprecedented challenges raised by the COVID-19 pandemic. A large search for identifying citizen science initiatives focusing on COVID-19 was performed on SciStarter, a global, online citizen science hub whose aim is to enable and encourage people to participate in scientific research (Hoffman et al., 2017). A search by keywords was conducted to retrieve citizen science projects intended to draw on the wisdom of the crowd to address the challenges related to COVID-19. Different terms were used to conduct the query (e.g. "COVID-19", "Corona Virus Disease" and "COVID") in order to access all potential citizen science projects of interest for this study. Altogether, 14 different initiatives were fetched. They were carefully screened by the authors to check their consistency with the study aims. Citizen science projects that were indexed with the "COVID" label, but that were not aimed at engaging lay people in a co-creating partnership directed to address the pandemic were excluded from the analysis. Hence, 7 projects were consistent with the study aims and included in the analysis: "CoronaReport", "COVID-19 Citizen Science Project", "COVID Near You/Outbreaks Near Me", "COVID Twitter Analysis", "CovidWatcher", "Respiratory Health Study", and "World Community Grid". The other citizen science projects were only indirectly related to the COVID-19 and did not entail lay people's involvement in tackling the pandemic.

As in the previous step, various secondary sources were consulted to collect in-depth information about these citizen science projects. Both projects' summary reported in the SciStarter web page and additional information retrieved on the main websites of the projects and on social media were investigated. All relevant data were stored in an electronic worksheet. A manual coding analysis was implemented, based on an inductive strategy intended to delineate the role of lay people in knowledge co-production and their contribution in advancing an open innovation approach to tackle the pandemic. Firstly, the authors individually examined the citizen science initiatives focusing on COVID-19. Individual reports were discussed in a meeting, which fostered the achievement of a consensus about the distinguishing attributes of citizen science initiatives. At the end of the meeting, a final report was drafted, which informed the research findings.

\section{Findings}

\subsection{Contextualizing citizen science to the healthcare ecosystem}

The first step of this study consisted of a realist literature review involving 30 scientific items. Publication years ranged between 2012 and 2021. Most of the records were published after $2015(80 \%)$. The majority were peer-reviewed articles published in international journals $(86.7 \%)$. Two editorials, one research note, and one conference proceeding were taken into consideration. On average, the items were cited 24 times $(\sigma=52.7)$, ranging from a minimum of one citation to a maximum of 288 citations. The number of citations reflected the publication year of scientific contributions, wherein the latest publications are relatively less cited as compared to earlier ones.

In line with the distinguishing attributes of a realist review, the report of the findings was aimed at eliciting the context, the mechanisms, and the outcomes of citizen science in healthcare. An overview of the key results obtained from the review of the literature is presented in Table 1. Citizen science projects in healthcare show peculiar features, that can be articulated in four main approaches to citizen science (Broeder et al., 2018):

(1) Crowdsourcing. Limited degree of lay people involvement in the accomplishment of research activities and innovation efforts. Citizen scientists basically act as data collectors and/or tabulators, participating in projects that are led by expert scientistsit is not characterized by lay people involvement in co-design of research endeavours. 
Citizen-science

\begin{tabular}{llll} 
attributes & Mechanisms & Main outcomes & Main references \\
\hline Crowdsourcing & $\begin{array}{l}\text { Web-based platforms and } \\
\text { infrastructures to recruit and } \\
\text { retain citizen scientists in }\end{array}$ & $\begin{array}{l}\text { Training of machine learning } \\
\text { technologies to foster big data } \\
\text { analytics }\end{array}$ & $\begin{array}{l}\text { Katapally et al. } \\
\text { (2018), Meakin } \\
\text { et al. (2019) }\end{array}$
\end{tabular}

\section{2}

professional-led research projects; limited degree of lay people involvement in the codesign of research activities

Distributed Web-based platforms and mobile intelligence devices are concomitantly exploited to enable lay people to perform data collection and data analysis in a perspective of distributed inquiry; alongside hard mechanisms, some soft mechanisms are implemented to ensure lay people training and durable involvement

Participatory Web-based platforms and digital science tools are primarily exploited to establish a co-creating relationship between lay people and expert scientists; soft mechanisms are significantly used to boost the establishment of fair exchanges between citizen scientists and expert scientists

Extreme citizen science Web-based platforms gather lay people who led research initiatives that are intended to push forward scientific knowledge; soft mechanisms are

Creative collective thinking and lay people increased awareness of health-related issues

Kovacic et al. (2014), Lee et al. (2018)

Innovative idea generation and advancement of individual and collective health-related

Den Broeder et al. (2018), Katapally knowledge et al. (2020)

Establishment of a community-

Kempner and based and collaborative model Bailey (2019), of care based on personalized Ashepet et al. medicine and openness (2021) citizen scientists' motivation and engagement in citizen science

Table 1.

An overview of citizenscience projects' attributes from the realist literature review

(2) Distributed intelligence. Citizen scientists have additional roles alongside data collection and transcription. The success of citizen science relies on volunteers' thinking and on their involvement in evidence's interpretation and classification.

(3) Participatory science. Lay people are significantly engaged in knowledge co-production, and they have a voice in defining problems and articulating the process of knowledge development. Notwithstanding, the citizen science project is led by expert scientists.

(4) Extreme citizen science. Lay people co-led the citizen science project, behaving as cocreating partners of expert scientists to generate knowledge and encourage innovation.

Drawing on this taxonomy, citizen scientists are assigned with varying responsibilities in accomplishing knowledge co-production efforts. Firstly, they may perform as members of the crowd, delivering big data to expert scientists that may corroborate scientific evidence established on conventional clinical data (Swan, 2012). Secondly, they may act as co-producing 
partners of expert scientists, collaborating with them in the co-design and co-delivery of research endeavours and contributing both in data collection and evidence interpretation (Grant et al., 2019). Lastly, lay people may act as the main driver of research activities, guiding the process of distributed data collection and extracting relevant information from retrieved data (Gimbert and Lapointe, 2015). Different mechanisms enable lay people's engagement in citizen science projects. Such mechanisms include the design of hard infrastructures to promote and sustain citizen scientists' involvement and the implementation of soft interventions to boost the establishment of a co-creating partnership between expert scientists and lay people (Palumbo et al., 2021). Two hard ingredients are concomitantly required in the recipe for effective citizen science projects. On the one hand, advisory boards composed of representatives of expert scientists and lay people should be enacted to set the conditions for a fair and equitable partnership targeted to knowledge co-production (Patel et al., 2016). On the other hand, focused web-based portals and platforms should be settled to gather citizen scientists and to provide them with the basic information and resources to participate in scientific research (Chung et al., 2016). Digital platforms are especially useful to facilitate the virtual encounter of expert scientists and lay people (Puhan et al.,2018) and to guide the latter throughout the participatory approach to scientific research (Steinemann et al., 2018). This is possible by providing lay people with tailored educational materials intended to empower them to perform as knowledge coproducers (Valle et al., 2018) and value co-creators (Katapally et al., 2018) and by developing proper digital tools that foster the continuous exchange of data and information (Younis et al., 2019).

Soft interventions complement hard mechanisms and are intended to act on the attitudes and behaviors of citizen scientists, encouraging them to enter a durable co-producing relationship with expert scientist (Ashepet et al., 2021). Soft initiatives involve empowering lay people to participate in citizen science projects through training activities aimed at increasing the individual and collective awareness of their potential contribution in scientific research (Watson et al., 2020), building fair relationships based on trust and loyalty amongst citizen scientists and expert scientists (Rodríguez-Gómez et al., 2019), and tackling social and cultural factors that may trigger a limited involvement of underserved groups of the population in citizen science projects (Fiske et al., 2019). It is worth noting that digital tools may establish a bridge between hard and soft mechanisms, creating a positive environment for lay people involvement in citizen science through gamification (Cigarini et al., 2018) and edutainment (Laut et al., 2015).

Literature has associated manifold outcomes to citizen science. Sticking to a crowdsourcing approach to citizen science, it has been argued that lay people have a critical role in training machine learning algorithms to deal with big data (Meakin et al., 2019) and in supporting expert scientists to accomplish low value-added and time-spending data classification (Lee et al., 2017). Besides, drawing on a distributed-intelligence perspective, citizen scientists' involvement entails a greater awareness of health-related issues among lay people, which fosters the development of creative thinking (Dick, 2017) and paves the way for their engagement in participatory research activities (Kovacic et al., 2014). From this standpoint, citizen science nurtures ideas' generation intended to advance the functioning of the healthcare ecosystem (Tran et al., 2019), as well as the development of impactful health recommendations in a perspective of value co-creation (Kempner and Bailey, 2019). Lastly, citizen science may lead to the establishment of a community-based and collaborative model of care (Díez et al., 2018), which relies on personalized medicine and openness (Beck et al., 2018; Tzovaras et al., 2019).

\subsection{The peculiar attributes of citizen science projects in the healthcare setting}

Three completed citizen science projects focusing on healthcare-related issues were retrieved from Zooniverse. A detailed account of the characteristics of these initiatives follows. Table 2 
EJIM

25,6

\section{4}

Table 2.

The characteristics of completed healthcare citizen-science projects hosted on Zooniverse

Citizen-

science

project

Main purpose Approach

Mechanisms

Outcomes

Cell Analysing tissue Crowdsourcing: lay

Slider samples and cells people classify cells' to determine the images, following number and the standard guidelines type of ill cells

and protocols designed by expert scientists

Etch a Cell

Where are my body organs?
Segmenting cells and obtaining information about the structures that make up molecules, cells and tissues
Crowdsourcing: lay people autonomously analyze cells' images, segmenting their nucleus according to prescriptions and guidelines asynchronously provided by expert scientists

Collecting evidence about the anatomical knowledge of the general public and about sociodemographic and cultural factors influencing individual anatomical knowledge
Crowdsourcing: lay people self-appraise their knowledge by undertaking a quiz about anatomy
Hard mechanisms aimed at standardizing lay people contribution in classification activities and at training them. Limited use of soft mechanisms to ensure lay people engagement and retention

Hard mechanisms aimed at training lay people and at formalizing their tasks. Formalization of communication and information exchanges between expert scientists and lay people. Soft mechanisms intended to motivate lay people and sustaining their engagement in citizen science projects Predominantly hard mechanisms, intended to formalize and routinize the exchanges between lay people and expert scientists and standardizing the process of data collection
Nimble and effective analysis of large amount of data, accompanied by savings of expert scientists' time and resources. Training of automated algorithms and machine learning tools to foster big data analytics

Processing of large amounts of data. Training of deep learning tools to enhance big data analytics. Lay people's engagement in scientific research and acknowledgement of their formal contribution to the achievement of research aims

Construction of a large dataset to conduct scientific research. Promotion of public education about anatomy

reports a summary of the projects. Even though all of them can be classified as crowdsourcing citizen science initiatives, they show some peculiarities both in the mechanisms used to engage lay people and in the outcomes that were achieved through the establishment of a partnership between expert scientists and citizen scientists.

3.2.1 "Cell slider". "Cell slider" is a citizen science project led by Cancer Research UK, a charity established in the United Kingdom to promote and conduct cutting-edge research into the prevention, diagnosis, and treatment of cancer. It was launched on Zooniverse on October, 2012. The main aim of the project was to recruit a large number of people to accomplish a broad, crowdsourced analysis of large amount of data embedded in pictures and images of human cells. Citizen scientists were asked to visualize and analyze tissue samples provided by the institution that led the research project, spotting and highlighting particular features 
of cells according to protocols and research guidelines delivered by expert scientists. Hence, "Cell slider" can be conceived of as a crowdsourcing citizen science project, characterized by a limited involvement of lay people in the co-design of research activities.

As the virtual platform hosting citizen scientists, Zooniverse acted as the main mechanism to coordinate the exchange between lay people and expert scientists. Before starting their classification activities, citizen scientists were asked to participate in a quick tutorial session intended to increase their confidence with the scientific tasks they had to accomplish. Furthermore, expert scientists implemented a standardization and formalization of individual activities to substantiate the engagement of citizen scientists in data analysis and classification. This permitted them to maximize the potential contribution of lay people to processing a large amount of data and, at the same time, allowed expert scientists to enhance lay people' coordination and to save time devoted to guidance and support to citizen scientists.

Amongst the key results of the project, a particular emphasis was placed on the citizen scientists' ability to collect details that were impossible to be retrieved by relying on machine learning and artificial intelligence exclusively. The inputs provided by lay people provided the research institutions with a nimbler and more effective analysis of a large amount of data, training automated algorithms and systems to enact big data analytics. However, only limited attention was paid to provide feedback about individual and collective performance. This hints that lay people education and empowerment about healthcare-related issues represented only a latent purpose of this citizen science project. Nevertheless, citizen scientists were found to be highly accurate in analyzing and classifying available data (Dos Reis et al., 2015).

3.2.2 "Etch a cell". "Etch a cell" is a citizen science project guided by the Francis Crick Institute, a biomedical research institution located London. The main research purpose was to understand the fundamental biology underlying human health and disease. Some characteristics of "Etch a cell" make it akin to "Cell slider". In particular, this initiative was primarily aimed at building a community of engaged lay people, who were asked to perform some basic data-elaboration activities based on images of cells produced using an electron microscope. Therefore, "Etch a cell" can be understood as a crowdsourcing citizen science project, in which citizen scientists are asked to perform some basic elaborations based on the instructions and guidelines provided in an asynchronous way by expert scientists.

As in the previous case, the web-based platform acted as the main mechanism to establish a bridge between expert scientists and lay people. Before being involved in accomplishing research activities, citizen scientists had to complete a brief training session, which included all basic information to effectively participate in segmenting the cells' nucleus. Some soft mechanisms were also implemented to sustain the lay people's engagement in the project. Inter alia, a talk section embedded in the institutional web page of "Etch a cell" permitted lay people to communicate with peers and with expert scientists to share their own experience, provide feedback on their research activities, and recommend improvements. Moreover, as an acknowledgement to lay people involvement in the project, the full names of all participants were published in the main web page of the initiative.

More than 7,000 lay people participated in this citizen science project, accomplishing more than 10,000 segmentations on 500 cells' representation. The main outcome of the project was twofold. It paved the way for a faster and less onerous segmentation and transcription of a large amount of data to support the training of automated algorithms, machine learning technologies, and artificial intelligence applications for big data analytics (Spiers et al., 2020). Besides, "Etch a cell" somewhat concurred to lay people's education and empowerment, engaging them in a vivid community of science enthusiasts who are aware of their potential contribution to the realization of more or less complicated research activities. Such a community, which is known as the Etchiverse, works on different citizen science projects that rely on the successful experience of "Etch a cell". 
EJIM

25,6
3.2.3 "Where are my body organs". "Where are my body organs" is a citizen science project led by a team of researchers affiliated to the medical school of Lancaster University and to the School of Medicine of the University of Namibia. Drawing on the findings of a preliminary study (Taylor et al., 2018), the project was intended to understand the anatomical knowledge of the global public and to shed light on the socio-demographic and cultural factors affecting individual knowledge about anatomy. Once again, a crowdsourcing approach to citizen science was adopted. However, in this circumstance lay people acted as the object - rather than the subject - of the project. By answering a quiz about anatomy, lay people provided the team of expert scientists with a large amount of data to collect evidence about the general public's anatomical knowledge.

The Zooniverse platform represented the main mechanism used to connect lay people and expert scientists. However, in light of the specificities of this project, citizen scientists were not asked to undertake a training activity or a tutorial before being involved in the project. In consideration of the limited degree of engagement of lay people in the co-design and codelivery of research activities, soft mechanisms were almost completely overlooked. The main outcome of the citizen science project manifested in the construction of a large dataset to assess the anatomical knowledge of lay people. Even though the enhancement of lay people's education and awareness of health-related issues was listed among the main aims of the project, no formal mechanisms and approaches were implemented to achieve this purpose. Similarly, a limited attention was paid to the establishment of an information exchange and a co-creating partnership between the team of expert scientists and the population of citizen scientists.

\subsection{Leveraging citizen science to address unprecedented healthcare challenges}

Table 3 synthesizes the key attributes of the citizen science projects intended to engage lay people to tackle the challenges raised by the COVID-19 pandemic. Seven projects indexed in the SciStarter platform were identified and analyzed for the purpose of this study. A detailed report of these project is articulated below.

3.3.1 "CoronaReport". "CoronaReport" is a citizen science project guided by the Scottish Collaboration for Public Health Research and Policy, a research center concerned with public health issues affiliated to the University of Edinburgh. The project's main aim is to democratize the process of data collection and reporting on the spread of COVID-19, enabling lay people to create personal, but anonymous diaries to store information about how the pandemic affected individual life and community dynamics. Lay people interact to exchange their views and perceptions about the impact of COVID-19 on individual and collective life. They are provided with some insights included in a user manual and a section on frequentlyasked questions to get all the information needed to participate in the project actively.

The engagement of citizen scientists is mediated by a digital app, which acts as the point of encounter between citizen scientists and expert scientists and as the field where data collection is accomplished. Ensuring lay people's access to the data and information recorded by peers and enacting a community of engaged citizen scientists, "CoronaReport" can be understood as a distributed intelligence project. Its key outcomes include the collection of a large amount of data to analyze the implications of COVID-19 on daily life and lay people's empowerment to make sense out of the implications of COVID-19 pandemic.

3.3.2 "COVID-19 citizen science project". The "COVID-19 Citizen Science Project" is led by a team of researchers affiliated to the University of California in San Francisco. This citizen science project adopts a crowdsourcing approach. In particular, lay people are asked to selfreport and share some personal data to provide expert scientists with first-hand and in-depth information to discover how the pandemic is spreading throughout the world and which factors are likely to boost further infections. The project basically relies on hard mechanism to 


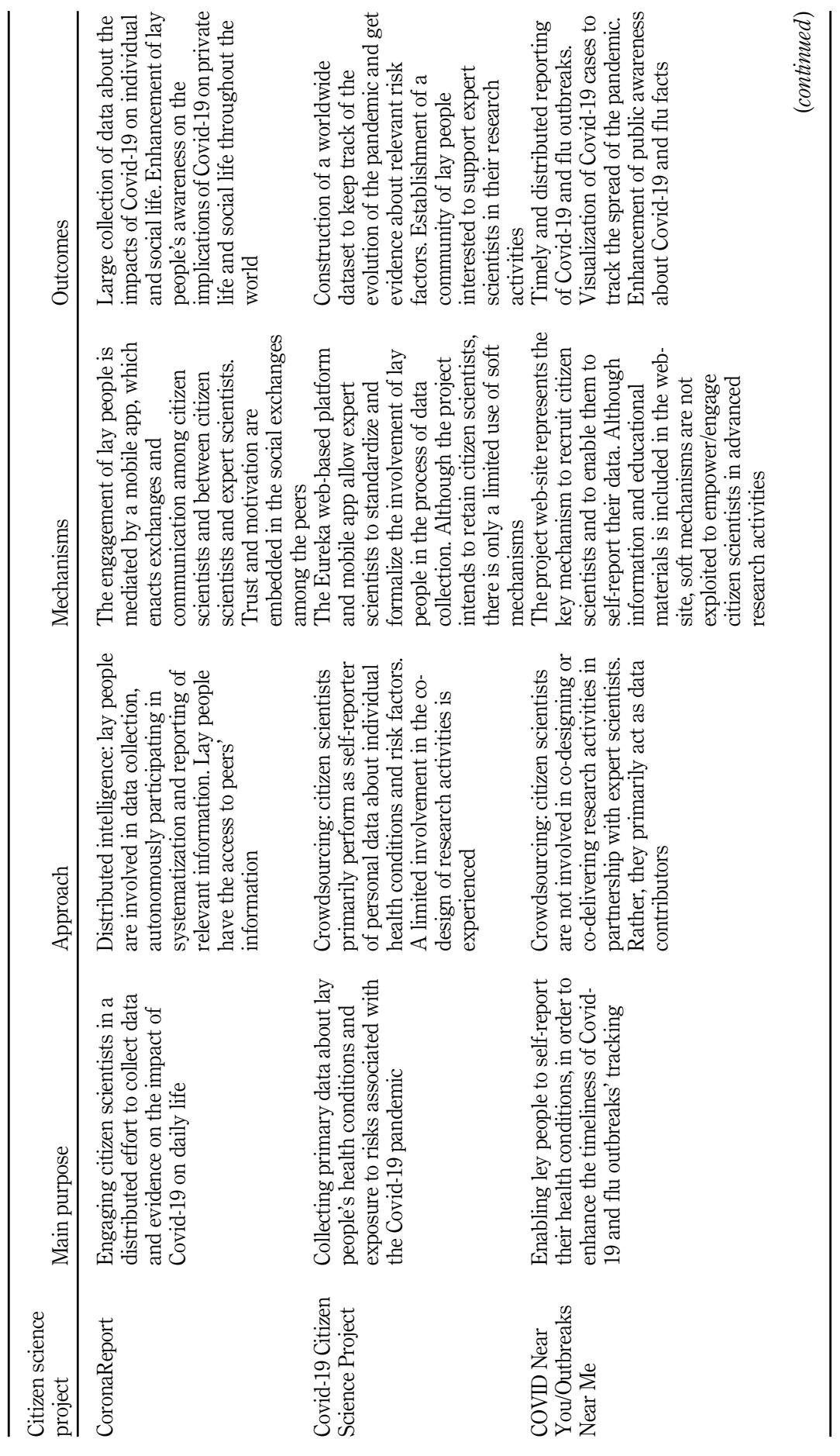

An open innovation approach

Table 3.

The characteristics of citizen-science projects aimed at tackling COVID-19 indexed in SciStarter 


\begin{tabular}{l} 
EJIM \\
25,6 \\
$\mathbf{3 7 8}$ \\
\hline
\end{tabular}

离

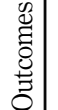

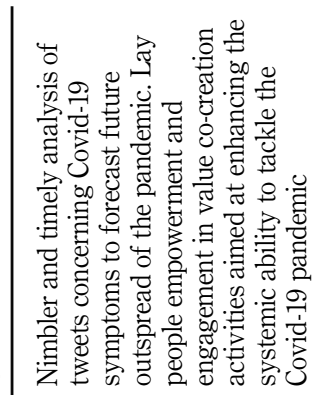

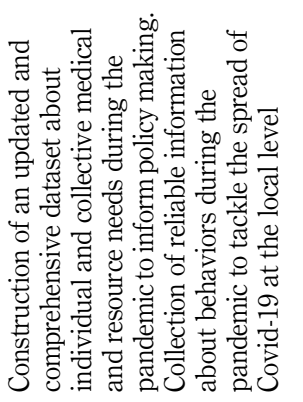

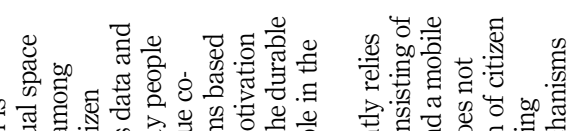

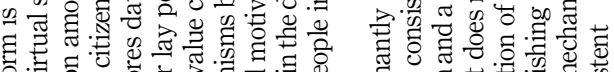

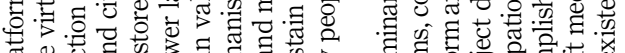

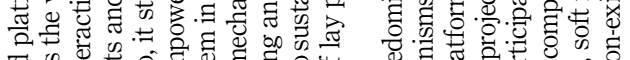

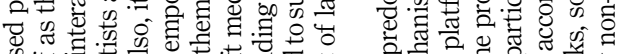

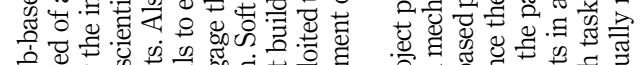
这.

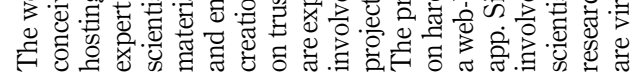

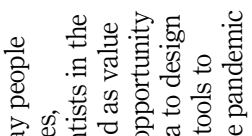
究

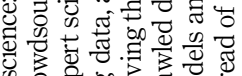

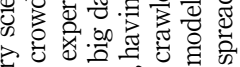
政

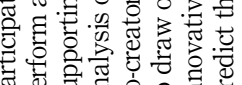

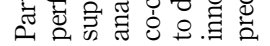

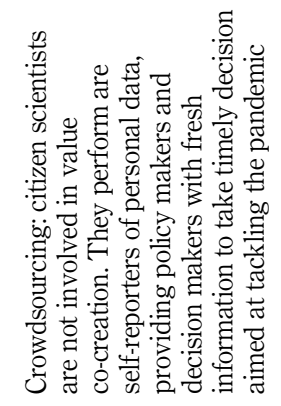
풍요

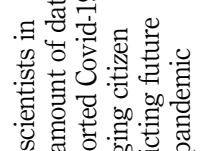

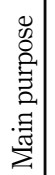
동

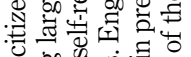
00. 요 沓要

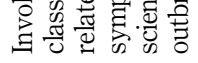

Table 3. 


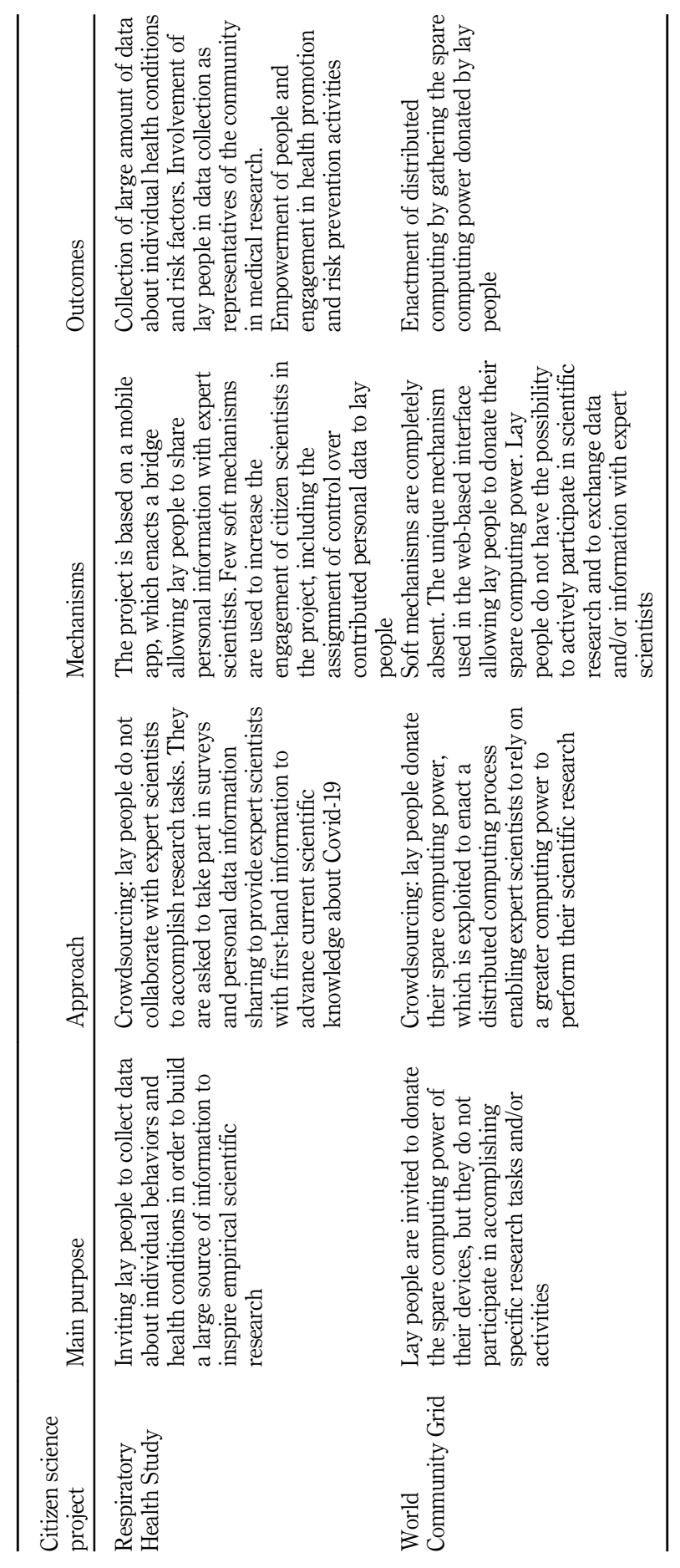

An open innovation approach

379

Table 3. 
EJIM

25,6

380

engage lay people in data collection. Such mechanisms are embedded in the Eureka webbased platform and mobile apps, which are powered by the National Institutes of Health $(\mathrm{NIH})$, a nation-wide research center that is part of the US Department of Health and Human Services. Lay people have to answer some survey questions, which permit expert scientists to access information about respondents' personal data and previous experiences.

Soft mechanisms are virtually non-existent, since citizen scientists are not involved in practical research activities alongside crowdsourcing their personal information. However, the "COVID-19 Citizen Science Project" aims at building a sustainable engagement of lay people in research initiatives, an example being the request for the recommendation of additional questions to be added to the survey addressed to the citizen scientists who participated in the earlier stages of the project. The project acts as an initial step to the development of long-term engagement of citizen scientists, paving the way for a full-fledged co-creating relationship between expert scientists and lay people. From this point of view, two main outcomes can be associated with the project. On the one hand, the initiative is targeted to the construction of a worldwide dataset to monitor COVID-19-related symptoms, to keep track of the impact of the pandemic, and to identify factors that help preventing infections. On the other hand, it fosters the establishment of a community of engaged lay people, who may be interested in undertaking more complex and challenging research activities to address the COVID-19 pandemic.

3.3.3 "COVID near you/outbreaks near me". The "COVID Near You/Outbreaks Near Me" is a project co-led by the Boston Children's Hospital and the Harvard Medical School in partnership with Ending Pandemics, a philanthropic organization involved in the design of demand-driven and sustainable solutions to report outbreaks of pandemics, and Flu Lab, a charitable organization performing cutting-edge research to help discover and share transformative solutions to influenza. It adopts a crowdsourcing approach, which makes it akin to the "COVID-19 Citizen Science Project". However, lay people act as contributors of data about health symptoms related to COVID-19 and flu outbreaks.

Citizen scientists are recruited via a dedicated web page, which functions as the main hard mechanism to involve lay people in data collection. Its main purpose is to collect evidence and identify trends about the diffusion of the COVID-19 pandemic before local and national public health agencies by empowering people to self-report their health conditions. Citizen scientists can visualize trends of COVID-19 spread at both the local and national level. Even though they can access some information materials and educational resources about the pandemic, their engagement in value co-creation in partnership with expert scientists is limited. The latter are assigned with data systematization and analysis, with an absent involvement of citizen scientists in data classification and/or elaboration. Hence, the project is predominantly intended to build a large dataset to nourish empirical scientific research performed by expert scientists.

3.3.4 "COVID Twitter Analysis". The "COVID Twitter Analysis" is an open-source project that is powered by the Interaction Data Lab and the Peer-Produced Research Lab of CRI Research Collaboratory, a research unit established by the University of Paris and the French Institut National de la Santé Et de la Recherche Médicale (INSERM). In this case, a participatory citizen science approach is embraced. Lay people have the opportunity to take part in a variety of research activities, which are inspired by an open-science spirit.

The web-based platform of the project is the virtual space hosting the exchanges among citizen scientists and expert scientists. The project is focused on the analysis of tweets about self-reported health symptoms related to COVID-19 in order to extract evidence and insights to anticipate and predict further outbreaks of the pandemic. Lay people are asked to examine the tweets crawled by expert scientists, classifying them according to their connection with the description of acute COVID-19-related symptoms. Several soft mechanisms are exploited to empower citizen scientists and engage them in participatory research. Among others, 
citizen scientists can download both tweets and annotation to contribute either individually or collectively in designing analytical tools to obtain evidence about COVID-19 outbreaks. Moreover, lay people can manage and visualize data to forecast forthcoming waves of the pandemic. The expected outcome of the project is twofold. Firstly, it allows expert scientists to draw on the voluntary contribution of lay people to analyze a large and continuously expanding mass of data. Secondly, it empowers citizen scientists and enables them to take part in challenging research activities aimed at increasing the healthcare ecosystem's ability to tackle the COVID-19 pandemic.

3.3.5 "CovidWatcher". The "CovidWatcher" project is steered by the Columbia University in collaboration with several community partners established in the New York city. It basically works as a crowdsourcing project, with lay people being asked to fill in several surveys intended to assess medical needs, resource needs, behaviors during the pandemic, and COVID-19 symptoms. The engagement of citizen scientists is realized though digital devices, consisting of web-based platforms and mobile apps. These hard mechanisms permit lay people to take part into data collection activities designed by expert scientists.

No soft mechanisms are introduced to promote the involvement of citizen scientists in advanced research activities aimed at value co-creation. The main purpose of the project is to collect a large and reliable set of data and information to inspire policy making and decision making of institutions involved in tackling the implications of COVID-19 at the individual and collective levels. Even though citizen scientists are enabled to explore and visualize data, they are not engaged in participatory research aimed at exploiting the wisdom of the crowd against the pandemic.

3.3.6 "Respiratory Health Study". The "Respiratory Health Study" is a citizen science project powered by Google Health Studies. It is conducted in collaboration with the Harvard Medical School and the Boston Children's Hospital. Echoing the approach taken in most of initiatives reported above, this project sticks to a crowdsourcing model of citizen science. Going more into details, lay people indirectly interact with expert scientists using a mobile app, which allows them to monitor their own health-related and behavioral data, to share them with expert scientists, and to provide additional information to nourish empirical analysis by answering surveys.

Once again, far from performing as value co-creators and partners of expert scientists, lay people mainly behave as representatives of the community in medical research, providing expert scientists with first-hand data and information to obtain reliable evidence about strategies and initiatives to fight the outbreak of the pandemic. Acting as a virtual bridge to allow lay people to share their data with expert scientists, the mobile app is a repository of health information, which may support patient empowerment and engagement with health promotion and risk prevention activities.

3.3.7 "World Community Grid". The "World Community Grid" cannot be treated as a COVID-19-specific citizen science project, as it is a public computing grid coordinated by IBM to allow people to donate the spare computing power of their devices to enact a distributed computing process aimed at helping scientists in accomplishing their research endeavours. More specifically, lay people participating in this project undertake a passive role in the citizen science initiative. By logging in the web-based platform hosting the grid, they can donate their spare computing power, without performing any scientific task in collaboration with expert scientists. Donating their spare computing power, lay people unconsciously carry out simulated experiments on potential treatments for COVID-19 and accelerate research to tackle the pandemic.

The main outcome of the project is the expansion of the computing power on which expert scientists can rely to conduct their scientific research. Being not directly involved in accomplishing research activities, citizen scientists do not benefit from an enhancement of their expertise or awareness of their potential contribution to the advancement of scientific

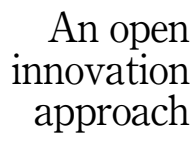

381 
EJIM

25,6

382

research. Consequently, it is a purely crowdsourcing citizen science project, with a very limited engagement of lay people in an empowerment process intended to increase their awareness of the challenges related to the COVID-19 pandemic.

\section{Discussion}

Figure 3 graphically summarize the main takeaways which can be collected from the research findings. Citizen science is slowly reshaping the way scientific research and innovation activities are accomplished in the healthcare ecosystem (Williams and Caley, 2021). Setting the stage for a collaboration between expert scientists and lay people, citizen science reframes conventional research activities accomplished in the healthcare domain, powering them with the contribution of the crowd (Borda et al., 2019). Moreover, citizen science enacts a process of democratization of scientific knowledge, letting lay people to enter a co-creating dialogue with expert scientists in order to steer the future attributes of healthcare (Woolley et al., 2016). Lastly, yet importantly, citizen science boosts public education and appreciation of timely and relevant health-related issues, concurring in underpinning their literacy and their ability to properly function in modern societies (Den Boeder et al., 2018).

Further steps are needed to overcome the rhetoric of lay people involvement in scientific research and to make citizen science a reality for healthcare institutions. Engaging lay people in knowledge co-production and innovation is key to achieve an increased quality of care in a perspective of people-centredness and to enhance the appropriateness of risk prevention and health promotion interventions (King et al., 2021). However, drawing on the research findings, several shortcomings affect the exploitation of citizen science to boost the innovation capability of healthcare institutions. Even when unprecedented health-related challenges are concerned, such as the COVID-19 pandemic (Katapally, 2020), lay people are primarily involved in innovation endeavors as sensors and collectors of data, who enhance the expert scientists' ability to build large and comprehensive datasets to perform their research activities in a nimbler and more effective way (D'Ignazio and Zuckerman, 2017). In other words, lay people's involvement primarily serves the expert scientists' need for obtaining large amounts of information (Maramis et al., 2019) and/or to analyze, transcribe, and classify available data to train machine-learning algorithms and artificial intelligence tools

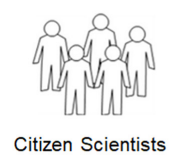

Citizen Scientists
Figure 3.

A graphical representation of the study's results

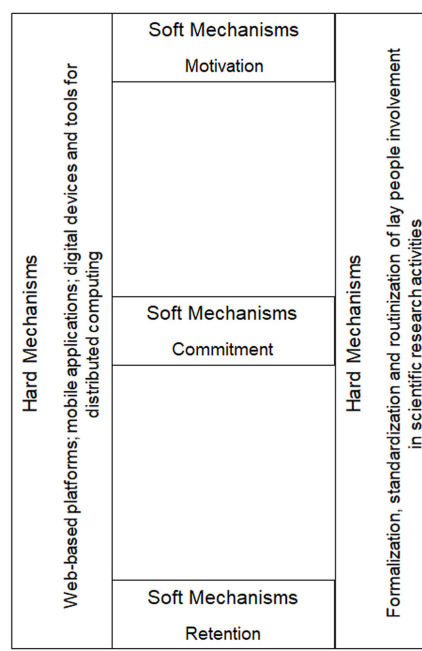

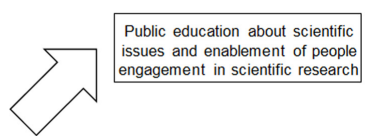
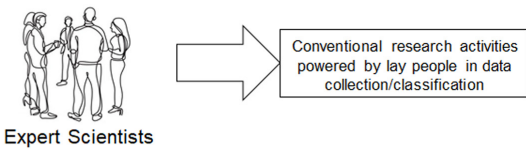

Expert Scientist

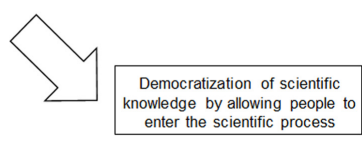


(Koepnick et al., 2019). Whilst this enacts a distributed computation process (Fisher et al., 2012), it falls short in enabling lay people to contribute in knowledge co-production and value co-creation actively (Palumbo et al., 2021), thus undermining the positive implications of citizen science on the democratization of science and on the enhancement of individual and collective literacy (Woolley et al., 2016).

Web-based platforms and mobile applications are exploited as the fundamental mechanisms to establish a bridge between expert scientists and lay people. However, far from implementing a rich and intense connection among lay people and expert scientists, such mechanisms are primarily used to formalize and routinize citizen scientists' participation in research activities, with limited attention paid to their empowerment and engagement in co-producing knowledge (Ali et al., 2021). Soft mechanisms, which aim at leveraging lay people's motivation and at boosting their involvement and retention in citizen science projects, are generally embedded in hard mechanisms and poorly exploited to foster citizen scientists' commitment to scientific research (Palumbo et al., 2021). This greatly reduces the expert scientists' ability to build a direct and co-creating relationship with lay people, who are seldom asked to partake in the co-design and co-delivery of research endeavors (Barrie et al., 2019). Training and asynchronous tutorial activities are developed to prepare lay people to perform basic and low value-added research endeavors. Exchanges between expert scientists and citizen scientists are indirect and focused on delivering to the latter the basic skills they need to smoothly participate in scientific efforts, with a limited attention paid to their enablement for value co-creation (Gristwood, 2019).

This paves the way for the preponderance of the crowdsourcing approach to citizen science in health care. It is consistent with the expert scientists' expectation to obtain an additional and relatively inexpensive processing and computing capability to collect and handle big data. However, it is not fully in line with the acknowledgement of a greater role to lay people in inspiring and driving the innovation paths undertaken by healthcare institutions. In spite of these considerations, the study findings point out that some gains can be offered by the involvement of citizen scientists in crowdsourcing citizen science. In particular, two indirect advantages are associated with it. On the one hand, lay people's engagement in data collection, analysis, and classification may foster a process of individual activation, which paves the way for a better knowledge of timely scientific challenges, thus contributing to advancing the scientific and health literacy of the public. On the other hand, by nurturing the awareness of individual and collective potential contribution of lay people to the accomplishment of scientific research, their participation in crowdsourcing citizen science may be conceived of as a first step for a greater involvement in distributed intelligence or participatory research projects, which are intended to democratize science and to empower citizen scientists to act as knowledge co-producers and value co-creators in partnership with expert scientists.

The study results provide us with some cues to answer the RQs and to advance what we currently know about citizen science in healthcare. Although the extant literature has largely emphasized the growing importance of citizen science and its implications on the reconfiguration of conventional scientific research models (Bonney et al., 2016a, b), a constraining approach to lay people's involvement is still prevailing in the healthcare ecosystem (Riesch and Potter, 2013). Lay people are predominantly conceived as mere contributors of information or, at best, as classifiers of data, working under the continuous (although indirect and mediated by digital tools) supervision of expert scientists. Hence, a crowdsourcing perspective inspires most of attempts that are directed at involving lay people in accomplishing research activities in collaboration with healthcare institutions. Whilst crowdsourcing is an important form of citizen science, initiating a dialogue between expert scientists and lay people to advance the public understanding of science (Del Salvio et al., 2016), it does suffer from some relevant limitations. Among others, it applies the 
EJIM

25,6

384

transformative power of citizen science to lay people, exclusively. Indeed, it does not necessarily require a transition of extant research infrastructures and scientific processes implemented by expert scientists, who may replicate conventional approaches to knowledge production, regardless of lay people involvement (Bela et al., 2016). This urges us to question whether lay people's participation in scientific research in healthcare is a reality or a rhetoric (Woolley et al., 2016).

Targeted policy and management interventions are imperative to realize the full potential of citizen science in healthcare and to advance lay people's engagement in inspiring and moulding innovation dynamics of healthcare institutions. Health policies intended to affirm people-centredness in the functioning of the healthcare ecosystem should acknowledge the role that lay people may play in envisioning the future shapes of healthcare delivery models. People-centredness should not be conceived as a sheer customer-orientation of healthcare institutions, which incites health services' providers to revise their relationship with patients in a perspective of increased quality of the patient-provider relationship. Rather, it should be contextualized as a new philosophy inspiring the identity of the healthcare ecosystem, whose structural attributes and operational processes should be arranged in light of the distinguishing needs and value expectations of patients. This calls for a larger participation of lay people throughout the steps of the value creation process enacted by healthcare institutions, ranging from the delivery of health promotion and risk prevention services to the development of new solutions to enhance the appropriateness and the effectiveness of care.

At the same time, proper management interventions are required to sustain citizen science projects and to encourage the transition from a crowdsourced approach to lay people's involvement to a distributed and participatory approach to scientific research. Although necessary to establish a bridge between expert scientists and lay people, hard mechanisms are not enough to underpin the viability of citizen science projects and to support lay people's commitment in scientific research. Healthcare institutions interested in exploiting the wisdom of the crowd in innovating healthcare delivery models should rely on soft mechanisms, empowering lay people to actively participate in knowledge co-production in partnership with expert scientists. This involves arranging adequate motivational measures, training sessions, and formal and informal rewards to align the perspectives of expert scientists and citizen scientists and to make the latter committed to co-producing scientific knowledge and co-creating value in collaboration with the former.

\section{Conclusion}

\subsection{Study limitations and avenues for further development}

Acknowledging the study limitations allows us to advance our interpretation of the study findings. The qualitative, cross-sectional approach used in this article prevented us from obtaining lengthwise evidence of lay people's involvement in citizen science projects (Jackson et al., 2015). Nevertheless, it permitted us to get an overview of the state of the art, which triggers interesting avenues for further developments. Besides, the breadth of this research was constrained by the focus on web-based citizen science platforms to retrieve relevant citizen science projects. Notwithstanding, since Zooniverse and SciStarter are the most popular platforms hosting citizen science projects (Vohland et al., 2021), it can be argued that focusing the research query on these two sources did not undermine the representativeness of our research. Lastly, whilst the mixed methodology employed in this article permitted us to get in-depth qualitative insights into citizen science in healthcare, it did not herald the collection of compelling quantitative evidence of the implications of lay people's involvement on the advancement of scientific knowledge (Jordan et al., 2015).

Further research is required to shed light on the participation of citizen scientists in initiatives intended to democratize scientific knowledge production in healthcare. Attention 
should be primarily paid to the dynamics of lay people's involvement and engagement in citizen science initiatives, accounting for the ethics of citizen scientists' participation in accomplishing research endeavors. Most of citizen science approaches are not tailored to the specific needs and resources of underprivileged group of the population, such as minorities and people living with disabilities. This undermines both the democratization of scientific research and the comprehensive engagement of people in value co-creation. In addition, issues related to the protection of personal data of people who accept to participate in citizen science initiatives should be addressed to overcome legal and institutional obstacles to the spread of participatory research.

Further empirical studies are greatly needed to assess the contribution of citizen scientists to the advancement of scientific knowledge. To the best of the authors' knowledge, there is still limited agreement on the impact of lay people's engagement on the advancement of scientific research. This may constrain both the healthcare institutions' proactiveness to espouse a citizen science-based model to conduct scientific research and the lay people's willingness to partake in participatory research. Finally, yet importantly, a review of existing participatory citizen science projects in healthcare is required to contextualize the drivers that stimulate lay people's engagement in co-creating efforts intended to push forward scientific knowledge targeted to health promotion and risk prevention.

\subsection{Study contribution}

Citizen science reconfigures the process of scientific knowledge production according to a value co-creation perspective. Some ambiguities characterize the state of the art of citizen science in healthcare. Even though it has been understood as a people-centric model of knowledge generation, it seems that a tension towards techno-centricity and a crowdsourcing orientation diminish the degree of people-centredness in citizen science projects. In most of the cases, lay people are involved in routinary research activities, such as self-reporting of personal data and evidence classification, which slightly contribute to their empowerment for the purpose of value co-creation. In other words, the involvement of lay people in accomplishing scientific endeavours is put at the service of technological advancements. Alongside allowing expert scientists to smoothly process huge amounts of data, activities contributed by citizen scientists are crucial to train machine-learning algorithms and artificial-intelligence tools, which provoke an estrangement of lay people from the democratization of science. Hence, there is the risk that citizen science falls short in its attempt to engage lay people in a fruitful and sustainable debate with expert scientists, which is essential to enhance scientific literacy and awareness of relevant research issues.

Crowdsourcing may be understood as the initial step of the journey which brings us towards the democratization of science and to the involvement of lay people in the establishment of a co-creating partnership with expert scientists. For this to happen, tailored interventions should be implemented to take advantage of the contact among lay people and expert scientists, transforming it into an enabling process. Lay people's empowerment has a twofold aim. Firstly, it provides citizen scientists with the basic skills and expertise that are needed to have an active role in the community for the purposes of health promotion and risk prevention, thus making the transition toward people-centered healthcare ecosystems a reality. Secondly, it sustains lay people's awareness of their contribution to the advancement of scientific knowledge, determining a greater willingness and desire to partner with expert scientists and to be actively involved in knowledge co-production.

Obviously, implementing citizen science in the healthcare context is not free from concerns. Challenges related to both the privacy and the ethics of sharing personal healthrelated data across a multitude of actors composing the healthcare ecosystem should be carefully addressed. Besides, attention should be paid to formally and informally 
EJIM

25,6

acknowledging the contribution of lay people to the advancement of scientific knowledge and making their role in value co-creation explicit. Lastly, the dehumanizing effect of exploiting web-based platforms and mobile apps to implement citizen science initiatives should be overcome, putting emphasis on the direct, co-creating relationship between lay people and expert scientists.

\section{References}

Akaka, M.A. and Vargo, S.L. (2014), "Technology as an operant resource in service (eco)systems", Information Systems and E-Business Management, Vol. 12 No. 1, pp. 367-384.

Ali, M.U., Mishra, B.K., Thakker, D., Mazumdar, S. and Simpson, S. (2021), "Using citizen science to complement IoT data collection: a survey of motivational and engagement factors in technology-centric citizen science projects", IoT, Vol. 2 No. 2, pp. 275-309.

Ashepet, M.G., Jacobs, L., Van Oudheusden, M. and Huyse, T. (2021), "Wicked solution for wicked problems: citizen science for vector-borne disease control in Africa", Trends in Parasitology, Vol. 37 No. 2, pp. 93-96.

Barile, S. and Polese, F. (2010), "Smart service systems and viable service systems: applying systems theory to service science", Service Science, Vol. 2 Nos 1/2, pp. 21-40.

Barrie, H., Soebarto, V., Lange, J., Mc Corry-Breen, F. and Walker, L. (2019), "Using citizen science to explore neighbourhood influences on ageing well: pilot project", Healthcare, Vol. 7 No. 4, p. 126.

Beck, S., Berner, A.M., Bignell, G., Bond, M., Callanan, M.J., Chervova, O., Conde, L., Corpas, M., Ecker, S., Elliott, H.R., Fioramonti, S.A., Flanagan, A.M., Gaentzsch, R., Graham, D., Gribbin, D., GuerraAssunção, J.A., Hamoudi, R., Harding, V., Harrison, P.L., Herrero, J., Hofmann, J., Jones, E., Khan, S., Kaye, J., Kerr, P., Libertini, E., Marks, L., McCormack, L., Moghul, I., Pontikos, N., Rajanayagam, S., Rana, K., Semega-Janneh, M., Smith, C.P., Strom, L., Umur, S., Webster, A.P., Williams, E.H., Wint, K. and Wood, J.N. (2018), "Personal genome project UK (PGP-UK): a research and citizen science hybrid project in support of personalized medicine”, BMC Medical Genomics, Vol. 11 No. 1, p. 108.

Beier, K., Schweda, M. and Schicktanz, S. (2019), "Taking patient involvement seriously: a critical ethical analysis of participatory approaches in data-intensive medical research", BMC Medical Informatics and Decision Making, Vol. 19, p. 90.

Bela, G., Peltola, T., Young, J.C., Balázs, B., Arpin, I., Pataki, G., Hauck, J., Kelemen, E., Kopperoinen, L., Van Herzele, A., Keune, H., Hecker, S., Suškevičs, M., Roy, H.E., Itkonen, P., Külvik, M., László, M., Basnou, C., Pino, J. and Bonn, A. (2016), "Learning and the transformative potential of citizen science", Conservation Biology, Vol. 30 No. 5, pp. 990-999.

Bendermacher, G.W.G., oude Egbrink, M.G.A., Wolfhagen, I.H.A.P. and Dolmans, D.H.J.M. (2017), "Unravelling quality culture in higher education: a realist review", Higher Education, Vol. 73 No. 1, pp. 39-60.

Benis, A., Tamburis, O., Chronaki, C. and Moen, A. (2021), "One digital health: a unified framework for future health ecosystems", Journal of Medical Internet Research, Vol. 23 No. 2, e22189.

Bergerum, C., Thorn, J., Josefsson, K. and Wolmesjö, M. (2019), "How might patient involvement in healthcare quality improvement efforts work-a realist literature review", Health Expectations, Vol. 22 No. 5, pp. 952-964.

Bergman, E.M.L. (2012), "Finding citations to social work literature: the relative benefits of using web of science, scopus, or google scholar", The Journal of Academic Librarianship, Vol. 38 No. 6, pp. 370-379.

Best, A., Greenhalgh, T., Lewis, S., Saul, J.E., Carroll, S. and Bitz, J. (2012), "Large-system transformation in health care: a realist review", Milbank Quarterly, Vol. 90 No. 3, pp. 421-456.

Bjørkquist, C., Ramsdal, H. and Ramsdal, K. (2015), "User participation and stakeholder involvement in health care innovation - does it matter?", European Journal of Innovation Management, Vol. 18 No. 1, pp. 2-18. 
Bonney, R., Cooper, C. and Ballard, H. (2016a), "The theory and practice of citizen science: launching a new journal", Citizen Science: Theory and Practice, Vol. 1 No. 1, pp. 1-4.

Bonney, R., Phillips, T.B., Ballard, H.L. and Enck, J.W. (2016b), "Can citizen science enhance public understanding of science?", Public Understanding of Science, Vol. 25 No. 1, pp. 2-16.

Borda, A., Gray, K. and Downie, L. (2019), "Citizen science models in health research: an Australian commentary", Online Journal of Public Health Informatics, Vol. 11 No. 3, p. e23.

Broeder, L.D., Devilee, J., Van Ores, H., Jantine, S.A. and Wagemakers, A. (2018), "Citizen science for public health", Health Promotion International, Vol. 33 No. 3, pp. 505-514.

Buyx, A., Del Savio, L., Prainsack, B. and Völzke, H. (2017), "Every participant is a PI. Citizen science and participatory governance in population studies", International Journal of Epidemiology, Vol. 46 No. 2, pp. 377-384.

Chung, A.E., Sandler, R.S., Long, M.D., Ahrens, S., Burris, J.L., Martin, C.F., Anton, K., Robb, A., Caruso, T.P., Laeger, E.J., Chen, W., Clark, M., Myers, K., Dobes, A. and Kappelman, M.D. (2016), "Harnessing person-generated health data to accelerate patient-centered outcomes research: the Crohn's and colitis foundation of America PCORnet patient powered research network (CCFA partners)", Journal of the American Medical Informatics Association, Vol. 23 No. 3, pp. 485-490.

Ciasullo, M.V., Cosimato, S. and Douglas, A. (2017), "Customer-centric service innovation in health care: findings from a case study", Sinergie Italian Journal of Management, Vol. 35 Nos Sep-Dec, pp. 155-176.

Ciasullo, M.V., Manna, R., Cavallone, M. and Palumbo, R. (2020), "Envisioning the future of health systems: exploratory insights from European countries”, Futures, Vol. 121, p. 102585.

Cigarini, A., Vicens, J., Duch, J., Sánchez, A. and Perelló, J. (2018), "Quantitative account of social interactions in a mental health care ecosystem: cooperation, trust and collective action", Scientific Reports, Vol. 8 No. 1, p. 3794.

Del Salvio, L., Prainsack, B. and Buyx, A. (2016), "Crowdsourcing the human gut. Is crowdsourcing also "citizen science?", Journal of Science Communication, Vol. 15 No. 3, p. A03.

Den Boeder, L., Devilee, J., Van Oers, H., Schuit, A.J. and Wagemakers, A. (2018), “Citizen Science for public health", Health Promotion International, Vol. 33 No. 3, pp. 505-514.

Díez, J., Gullón, P., Vázquez, M.S., Álvarez, B., Del Prado Martín, M., Urtasun, M., Gamarra, M., Gittelsohn, J. and Franco, M. (2018), "A community-driven approach to generate urban policy recommendations for obesity prevention”, International Journal of Environmental Research and Public Health, Vol. 15 No. 4, p. 635.

Dick, D.M. (2017), "Rethinking the way we do research: the benefits of community-engaged, citizen science approaches and non-traditional collaborators", Alcoholism: Clinical and Experimental Research, Vol. 41 No. 11, pp. 1849-1856.

D'Ignazio, C. and Zuckerman, E. (2017), “Are we citizen scientists, citizen sensors or something else entirely", in De Abreu, B.S., Mihailidis, P., Lee, A.Y.L., Melki, J. and McDougall, J. (Eds), International Handbook of Media Literacy Education, Routledge, Abingdon, pp. 193-210.

Dos Reis, F.J.C., Lynn, S.E., Ali, H.R., Eccles, D., Hanby, A., Provenzano, E., Caldas, C., Howat, W.J., McDuffus, L., Liu, B., Daley, F., Coulson, P., Vyas, R.J., Harris, L.M., Owens, J.M., Carton, A.F.M., McQuillan, J.P., Paterson, A.M., Hirji, Z., Christie, S.K., Holmes, A.R., Schmidt, M.K., GarciaClosas, M., Easton, D.F., Bolla, M.K., Wang, Q., Benitez, J., Milne, R.L., Mannermaa, A., Couch, F., Devilee, P., Tollenaar, R.A.E.M., Seynaeve, C., Cox, A., Cross, S.S., Blows, F.M., Sanders, J., de Groot, R., Figueroa, J., Sherman, M., Hooning, M., Brenner, H., Holleczek, B., Stegmaier, C., Lintott, C. and Pharoah, P.D.P. (2015), "Crowdsourcing the general public for large scale molecular pathology studies in cancer”, EBioMedicine, Vol. 2 No. 7, pp. 681-689.

Fisher, D., DeLine, R., Czerwinski, M. and Drucker, S. (2012), "Interactions with big data analytics", Interactions, Vol. 19 No. 3, pp. 50-59. 
EJIM

25,6

Fiske, A., Prainsack, B. and Buyx, A. (2019), "Meeting the needs of underserved populations: setting the agenda for more inclusive citizen science of medicine", BMJ Journal of Medical Ethics, Vol. 45 No. 1, pp. 617-622.

Gimbert, C. and Lapointe, F.J. (2015), "Self-tracking the microbiome: where do we go from here?", Microbiome, Vol. 3 No. 70, pp. 1-4.

Grant, A.D., Wolf, G.I. and Nebeker, C. (2019), “Approaches to governance of participant-led research: a qualitative case study", BMJ Open, Vol. 9 No. 1, e025633.

Greenhalgh, T., Jackson, C., Shaw, S. and Janamian, T. (2016), “Achieving research impact through cocreation in community-based health services: literature review and case study", Milbank Quarterly, Vol. 94 No. 2, pp. 392-429.

Gremyr, I. and Raharjo, H. (2013), "Quality function deployment in healthcare: a literature review and case study”, International Journal of Health Care Quality Assurance, Vol. 26 No. 2, pp. 135-146.

Gristwood, A. (2019), "How citizen science initiatives in healthcare and the environment are opening up new directions in research", EMBO Reports, Vol. 20 No. 8, e48797.

Hoffman, C., Cooper, C.B., Kennedy, E.B., Faroowue, M. and Cavalier, D. (2017), "SciStarter 2.0: a digital platform to foster and study sustained engagement in citizen science", in Ceccaroni, L. and Piera, J. (Eds), Analyzing the Role of Citizen Science in Modern Research, IGI Global, Hershey, PA, pp. 50-61.

Jackson, C.B., Østerlund, C., Mugar, C., DeVries Hassman, K. and Crowston, K. (2015), "Motivations for sustained participation in crowdsourcing: case Studies of citizen science on the role of talk", 48th International Conference on System Sciences, Hawaii, January, 5th/8th, IEEE.

Jordan, R., Crall, A., Gray, S., Phillips, T. and Mellor, D. (2015), "Citizen science as a distinct field of inquiry", BioScience, Vol. 65 No. 2, pp. 208-211.

Katapally, T.R., Bhawra, J., Leatherdale, S.T., Ferguson, L., Longo, J., Rainham, D., Larouche, R. and Osgood, N. (2018), "The SMART Study, a mobile health and citizen science methodological platform for active living surveillance, integrated knowledge translation, and policy interventions: longitudinal study", JMIR Public Health and Surveillance, Vol. 4 No. 1, p. e31.

Katapally, T.R. (2020), "A global digital citizen science policy to tackle pandemics like COVID-19", Journal of Medical Internet Research, Vol. 22 No. 5, e19357.

Kempner, J. and Bailey, J. (2019), "Collective self-experimentation in patient-led research: how online health communities foster innovation", Social Science and Medicine, Vol. 238 No. 1, p. 112366.

King, A.C., Odunitan-Wayas, F.A., Chaudhury, M., Rubio, M.A., Baiocchi, M., Kolbe-Alexander, T., Montes, F., Banchoff, A., Sarmiento, O.L., Bälter, K., Hinckson, E., Chastin, S., Lambert, E.V., González, S.A., Guerra, A.M., Gelius, P., Zha, C., Sarabu, C., Kakar, P.A., Fernes, P., Rosas, L.G., Winter, S.J., McClain, E. and Gardiner, P.A. (2021), "Community-based approaches to reducing health inequities and fostering environmental justice through global youth-engaged citizen science", International Journal of Environmental Research Public Health, Vol. 18 No. 3, p. 892.

Koepnick, B., Flatten, J., Husain, T., Ford, A., Silva, D.A., Bick, M.J., Bauer, A., Liu, G., Ishida, Y., Boykov, A., Estep, R.D., Kleinfelter, S., Nørgård-Solano, T., Wei, L., Players, F., Montelione, G.T., DiMaio, F., Popović, Z., Khatib, F., Cooper, S. and Bake, D. (2019), "De novo protein design by citizen scientists", Nature, Vol. 570 No. 1, pp. 390-394.

Kovacic, M.B., Stigler, S., Smith, A., Kidd, A. and Vaughn, L.M. (2014), "Beginning a partnership with photovoice to explore environmental health and health inequities in minority communities", International Journal of Environmental Research and Public Health, Vol. 11 No. 11, pp. 11132-11151.

Kraus, S., Schiavone, F., Pluzhnikova, A. and Invernizzi, A.C. (2021), "Digital transformation in healthcare: analyzing the current state-of-research", Journal of Business Research, Vol. 123, pp. 557-567.

Laut, J., Cappa, F., Nov, O. and Porfiri, M. (2015), "Increasing patient engagement in rehabilitation exercises using computer-based citizen science", PLoS One, Vol. 10 No. 3, e0117013. 
Lee, S.M. and Lim, S. (2018), Living Innovation, Emerald Publishing, Bingley.

Lee, Y.J., Arida, J.A. and Donovan, H.S. (2017), "The application of crowdsourcing approaches to cancer research: a systematic review", Cancer Medicine, Vol. 6 No. 11, pp. 2595-2605.

Lee, T.K., Crowston, K., Harandi, M., Østerlund, C. and Miller, G. (2018), "Appealing to different motivations in a message to recruit citizen scientists: results of a field experiment", Journal of Science Communication, Vol. 17 No. 1, p. A02.

Lega, F. and Palumbo, R. (2021), "Leading through the 'new normality' of health care”, Health Services Management Research, Vol. 34 No. 1, pp. 47-52.

Lim, W.M. and Ting, D.H. (2012), "Healthcare marketing: contemporary salient issues and future research directions", International Journal of Healthcare Management, Vol. 5 No. 1, pp. 3-11.

Lim, W.M. (2016), "Social media in medical and health care: opportunities and challenges”, Marketing Intelligence and Planning, Vol. 34 No. 7, pp. 964-976.

Lim, W.M. (2021), "A marketing mix typology for integrated care: the 10 Ps", Journal of Strategic Marketing, Vol. 29 No. 5, pp. 453-469.

Lundberg, N., Koch, S., Hägglund, M., Bolin, P., Davoody, N., Eltes, J., Jarlman, O., Perlich, A., Vimarlund, V. and Winsnes, C. (2013), "My care pathways - creating open innovation in healthcare", Studies in Health Technologies and Informatics, Vol. 192 No. 1, pp. 687-691.

Magnusson, P., Bergkvist, L. and Skålén, P. (2017), "Exploring patients as contributors to service innovation in primary healthcare", Innovation and Product Development Management Conference, Reykjavík, June 11th-13th, 24th, EIASM.

Maramis, C., Ioakimidis, I., Kilintzis, V., Stefanopoulos, L., Lekka, E., Papapanagiotou, V., Diou, C., Delopoulos, A., Kassari, P., Charmandari, E. and Maglaveras, N. (2019), "Developing a novel citizen-scientist smartphone app for collecting behavioral and affective data from children populations", 8th International Conference on Wireless Mobile Communication and Healthcare, Dublin, November, 14th/15th, Springer.

Masters, K., Oh, E.Y., Cox, J., Simmons, B., Lintott, C., Graham, G., Greenhill, A. and Holmes, K. (2016), "Science learning via participation in online citizen science", Journal of Science Communication, Vol. 3 No. 2, p. A07.

McNichol, E. (2012), "Patient-led innovation in healthcare: the value of the 'user' perspective", International Journal of Healthcare Management, Vol. 5 No. 4, pp. 216-222.

Meakin, J.R., Ames, R.M., Jeynes, C.G., Welsman, J., Gundry, M., Knapp, K. and Everson, R. (2019), "The feasibility of using citizens to segment anatomy from medical images: accuracy and motivation", PLoS One, Vol. 14 No. 10, e0222523.

Palumbo, R. (2016), "Contextualizing co-production of health care: a systematic literature review", International Journal of Public Sector Management, Vol. 29 No. 1, pp. 72-90.

Palumbo, R., Cosimato, S. and Tommasetti, A. (2017), "Dream or reality? A recipe for sustainable and innovative health care ecosystems", The TQM Journal, Vol. 29 No. 6, pp. 847-862.

Palumbo, R., Manna, R. and Douglas, A. (2021), "Toward a socially-distributed mode of knowledge production: framing the contribution of lay people to scientific research", International Journal of Transitions and Innovation Systems, Vol. 6 No. 4, pp. 381-402.

Patel, D.I., Winkler, P., Botello, J., Villarreal, J. and Puga, F. (2016), “The citizen scientist: communityacademic partnerships through translational advisory boards", Patient Education and Counseling, Vol. 29 No. 12, pp. 2087-2090.

Pauget, B. and Wald, A. (2018), "Creating and implementing organizational innovation: the role of professional identity and network embeddedness in healthcare organizations", European Journal of Innovation Management, Vol. 21 No. 3, pp. 384-401.

Pawson, R., Greenhalgh, T., Harvey, G. and Walshe, K. (2005), "Realist review - a new method of systematic review designed for complex policy interventions", Journal of Health Services Research and Policy, Vol. 10 No. 1, pp. 21-34. 
EJIM

25,6

390

Petersen, C., Austin, R.R., Backonja, U., Campos, H., Chung, A.E., Hekler, E.B., Hsueh, P.S., Kim, K.K., Pho, A., Salmi, L., Solomonides, A. and Valdez, R.S. (2020), "Citizen science to further precision medicine: from vision to implementation", Journal of the American Medical Informatics Association Open, Vol. 3 No. 1, pp. 2-8.

Pianykh, O.S., Guitron, S., Parke, D., Zhang, C., Pandharipande, P., Brink, J. and Rosenthal, D. (2020), "Improving healthcare operations management with machine learning", Nature Machine Intelligence, Vol. 2 No. 1, pp. 266-273.

Pranckute, R. (2021), "Web of science (WoS) and Scopus: the titans of bibliographic information in today's academic world", Publications, Vol. 9 No. 1, p. 12.

Puhan, M.A., Steinemann, N., Kamm, C.P., Müller, S., Kuhle, J., Kurmann, R., Calabrese, P., Kesselring, J. and von Wyl, V. (2018), "A digitally facilitated citizen-science driven approach accelerates participant recruitment and increases study population diversity", Swiss Medical Weekly, Vol. 148 No. 1, p. w14623.

Pushparajah, D.S., Geissler, J. and Westergaard, N. (2015), "EUPATI: collaboration between patients, academia and industry to champion the informed patient in the research and development of medicines", Journal of Medicines Development Sciences, Vol. 1 No. 1, pp. 74-80.

Randhawa, K., West, J., Skellern, K. and Josserand, E. (2020), "Evolving a value chain to an open innovation ecosystem: cognitive engagement of stakeholders in customizing medical implants", California Management Review, Vol. 63 No. 2, pp. 101-134.

Riesch, H. and Potter, C. (2013), "Citizen science as seen by scientists: methodological, epistemological and ethical dimensions", Public Understanding of Science, Vol. 23 No. 1, pp. 107-120.

Rodríguez-Gómez, O., Rodrigo, A., Iradier, F., Santos-Santos, M.A., Hundemer, H., Ciudin, A., Sannemann, L., Zwan, M., Glaysher, B., Wimo, A., Bonn, J., Johansson, G., Rodriguez, I., Alegret, M., Gove, D., Pinó, S., Trigueros, P., Kivipelto, M., Mathews, B., Ciudad, A., Ferreira, D., Bintener, C., Gurruchaga, M., Westman, E., Belger, M., Valero, S., Maguire, P., Krivec, D., Kramberger, M., Simó, R., Pérez Garro, I., Visser, P.J., Dumas, A., Georges, J., Jessen, F., Winblad, B., Shering, C., Stewart, N., Campo, L. and Boada, M. (2019), "The MOPEAD project: advancing patient engagement for the detection of 'hidden' undiagnosed cases of Alzheimer's disease in the community", Alzheimer and Dementia, Vol. 15 No. 6, pp. 828-839.

Schiavone, F. and Simoni, M. (2019), "Strategic marketing approaches for the diffusion of innovation in highly regulated industrial markets: the value of market access", Journal of Business and Industrial Marketing, Vol. 34 No. 7, pp. 1606-1618.

Schiavone, F., Leone, D., Sorrentino, A. and Scaletti, A. (2020), "Re-designing the service experience in the value co-creation process: an exploratory study of a healthcare network", Business Process Management Journal, Vol. 26 No. 4, pp. 889-908.

Schiavone, F., Mancini, D., Leone, D. and Lavorato, D. (2021), "Digital business models and ridesharing for value co-creation in healthcare: a multi-stakeholder ecosystem analysis", Technological Forecasting and Social Change, Vol. 166, p. 120647.

Secundo, G., Toma, A., Schiuma, G. and Passiante, G. (2019), "Knowledge transfer in open innovation: a classification framework for healthcare ecosystems", Business Process Management Journal, Vol. 25 No. 1, pp. 144-163.

Sehgal, S. and Gupta, G. (2019), "Converging resources and co-producing for innovation: evidence from healthcare services", European Journal of Innovation Management, Vol. 23 No. 3, pp. 429-453.

Simpson, R., Page, K.R. and De Roure, D. (2014), "Zooniverse: observing the world's largest citizen science platform”, 23rd International Conference on World Wide Web, Seoul, April 7th, ACM.

Skarlatidou, A., Hamilton, A., Vitos, M. and Haklay, M. (2019), "What do volunteers want from citizen science technologies? A systematic literature review and best practice guidelines", Journal of Science Communication, Vol. 18 No. 1, p. A02. 
Spiers, H., Songhurst, H., Nightingale, L., de Folter, J., Hutchings, R., Peddie, C.J., Weston, A., Strange, A., Hindmarsh, S., Lintott, C., Collinson, M.L. and Jones, M.L. (2020), Citizen Science, Cells and CNNs - Deep Learning for Automatic Segmentation of the Nuclear Envelope in Electron Microscopy Data, Trained with Volunteer Segmentations, bioRxiv, New York.

Steinemann, N., Kuhle, J., Calabrese, P., Kesselring, J., Disanto, G., Merkler, G., Pot, C., Ajdacic-Gross, V., Rodgers, S., Puhan, M.A. and von Wyl, V. (2018), "The Swiss multiple sclerosis registry (SMSR): study protocol of a participatory, nationwide registry to promote epidemiological and patient-centered MS research", BMC Neurology, Vol. 18 No. 1, p. 111.

Swan, M. (2012), "Crowdsourced health research studies: an important emerging complement to clinical trials in the public health research ecosystem", Journal of Medical Internet Research, Vol. 14 No. 2, p. e46.

Taylor, A.M., Diggle, P. and Wessels, Q. (2018), "What do the public know about anatomy? Anatomy education to the public and the implications", Anatomical Sciences Education, Vol. 11 No. 2, pp. 117-123.

Thakur, R., Hsu, S.H. and Fontenot, G. (2012), "Innovation in healthcare: issues and future trends", Journal of Business Research, Vol. 65 No. 4, pp. 562-569.

Thimbleby, H. (2013), "Technology and the future of healthcare", Journal of Public Health Research, Vol. 2 No. 3, p. e28.

Thune, T. and Gulbrandsen, M. (2017), "Combining knowledge to generate novelty: a study of disclosed ideas for life science inventions", European Journal of Innovation Management, Vol. 20 No. 3, pp. 446-462.

Tran, V.T., Riveros, C., Péan, C., Czarnobroda, A. and Ravaud, P. (2019), "Patients' perspective on how to improve the care of people with chronic conditions in France: a citizen science study within the ComPaRe e-cohort", BMJ Quality and Safety, Vol. 28 No. 11, pp. 875-886.

Tzovaras, B.G., Angrist, M., Arvai, K., Dulaney, M., Estrada-Galiñanes, V., Gunderson, B., Head, T., Lewis, D., Nov, O., Shaer, O., Tzovara, A., Bobe, J. and Ball, M.P. (2019), "Open humans: a platform for participant-centered research and personal data exploration”, Gigascience, Vol. 8 No. 6, pp. 1-13.

Ulahannan, J.P., Narayanan, N., Thalhath, N., Prabhakaran, P., Chaliyeduth, S., Suresh, S.P., Mohammed, M., Rajeevan, E., Joseph, S., Balakrishnan, A., Uthaman, J., Karingamadathil, M., Thomas, S.T., Sureshkumar, U., Balan, S. and Vellichirammal, N.N. (2020), "A citizen science initiative for open data and visualization of COVID-19 outbreak in Kerala, India", Journal of the American Medical Informatics Association, Vol. 27 No. 12, pp. 1913-1920.

Valle, N., Brishke, J., Ritzhaupt, A.D., Evans, C., Nelson, D.R. and Shenkman, E. (2018), "Using instructional design to support community engagement in clinical and translational research: a design and development case", Journal of Formative Design in Learning, Vol. 2 No. 1, pp. 20-35.

Vohland, K., Land-zandstra, A., Ceccaroni, L., Lemmens, R., Perelló, J., Ponti, M., Samson, R. and Wagenknecht, K. (2021), The Science of Citizen Science, Springer, Cham.

Wass, S. and Vimarlund, V. (2016), "Healthcare in the age of open innovation - a literature review", Health Information Management Journal, Vol. 45 No. 3, pp. 121-133.

Watson, K.S., Siegel, L.D., Henderson, V.A., Murray, M., Chukwudozie, I.B., Odell, D., Stinson, J., Ituah, O., Ben Levi, J., Fitzgibbon, M.L., Kim, S. and Matthews, P. (2020), "The SHARED Project: a novel approach to engaging African American men to address lung cancer disparities", American Journal of Mens' Health, Vol. 14 No. 5, pp. 1-11.

Wiggins, A. and Wilbanks, J. (2019), "The rise of citizen science in health and biomedical research", The American Journal of Bioethics, Vol. 19 No. 8, pp. 3-14.

Williams, S.J. and Caley, L. (2021), "Citizen involvement: what does it mean?", in Williams, S.J. and Caley, L. (Eds), Improving Healthcare Services, Springer, Cham, pp. 25-38.

Woolley, J.P., McGowan, M.L., Teare, H.J.A., Coathup, V., Fishman, J.R., Settersten, R.A. Jr, Sterckx, S., Kaye, J. and Juengst, E.T. (2016), "Citizen science or scientific citizenship? Disentangling the 
EJIM

25,6

392

uses of public engagement rhetoric in national research initiatives", BMC Medical Ethics, Vol. 17 No. 1, p. 33.

Yeung, A.W.K., Atanasov, A.G., Sheridan, H., Klager, E., Eibensteiner, F., Völkl-Kernsock, S., KleteckaPulker, M., Willschke, H. and Schaden, E. (2020), "Open innovation in medical and pharmaceutical research: a literature landscape analysis”, Frontiers in Pharmacology, Vol. 11 No. 1, p. 587526.

Younis, E.M.G., Kanjo, E. and Chamberlain, A. (2019), "Designing and evaluating mobile self-reporting techniques: crowdsourcing for citizen science”, Personal and Ubiquitous Computing, Vol. 23 No. 1, pp. 329-338.

\section{Corresponding author}

Rocco Palumbo can be contacted at: rocco.palumbo@uniroma2.it

For instructions on how to order reprints of this article, please visit our website: www.emeraldgrouppublishing.com/licensing/reprints.htm Or contact us for further details: permissions@emeraldinsight.com 